\title{
Gestión administrativa mediante la planificación operativa y financiera de las microempresas orenses de producción camaronera periodo 2019 - 2022
}

Fecha de recepción: 2021-12-06 Fecha de aceptación: 2022-01-20 • Fecha de publicación: 2022-02-10

Marjorie Katherine Crespo García ${ }^{1}$ Universidad Metropolitana del Ecuador, Ecuador marjoriekatherine07@gmail.com https://orcid.org/0000-0002-4260-1811

Martin Andrés Romero Lalangui ${ }^{2}$ Universidad Metropolitana del Ecuador, Ecuador mart.romero@tutanota.com https://orcid.org/0000-0002-7465-618X

Armando José Urdaneta Montiel ${ }^{3}$ Universidad Metropolitana del Ecuador, Ecuador aurdaneta@umet.edu.ec

https://orcid.org/0000-0002-9825-9453

Andreína Inés González Ordóñez ${ }^{4}$ Universidad Metropolitana de Ecuador, Ecuador aigonzalez@umet.edu.ec https://orcid.org/0000-0003-2209-2295

\section{RESUMEN}

La gestión administrativa es un proceso gerencial que permite a una organización ser proactiva en vez de reactiva, enfocada en herramientas financieras, planificaciones estratégicas e indicadores económicos. Sin embargo, el desinterés de los organismos de control hacia el sector microempresarial perpetua un amplio desconocimiento en lo administrativo y financiero, así mismo, la falta de recursos económicos y el comportamiento reacio al cambio limitan el desarrollo del 
mencionado sector. El objetivo de este estudio es elaborar la planificación operativa y financiera de las microempresas orenses, periodo 2019 al 2022, a través del presupuesto maestro, bajo normas internas. La investigación se categoriza como aplicada, de carácter correlativa, analítica y descriptiva, naturaleza no experimental y corte de tipo longitudinal, utilizando información de 416 microempresarios que permitió analizar la relación entre la presencia de instrumentos de control operativo-financiero y una efectiva dirección empresarial, ello a través de la identificación de factores que explican el comportamiento de variables de estudio como: nivel de control de las operaciones diarias, utilización de herramientas de gestión e implementación de instrumentos financieros, mismas que contribuyen a la gestión administrativa, el fortalecimiento y la competitividad; los resultados demuestran que la aplicación del direccionamiento estratégico, coadyuva al cumplimiento de los objetivos.

\section{PALABRAS CLAVE: microempresario, gestión administrativa, planificación estratégica, control operativo-financiero}

\section{ABSTRACT}

Administrative management is a managerial process that allows an organization to be proactive instead of reactive, focused on financial tools, strategic planning and economic indicators. However, the disinterest of the control agents towards the microenterprise sector perpetuates on a wide ignorance relate to the administrative and financial, also, the lack of financial resources and the reluctant behavior to change limit the development of the aforementioned sector. The objective of this study is to elaborate the operating and financial planification for the orense microenterprises, period 2019 to 2022, through the master budget, under internal rules. This investigation is categorized as applied, with a correlative, analytical and descriptive approach, a non-experimental nature and a longitudinal cut, using information of 416 microenterprises that allowed to analyze the relationship between the presence of operational-financial control instruments and an effective business management, this through the identification of factors that explain the study variables, such as: level of daily operational control, use of management tools and implementation of financial instruments, which contribute to administrative management, strengthening and competitiveness; the results show that the application of strategic directionship contributes to the fulfillment of organizational objectives. 


\section{Introducción}

América latina, siendo un territorio cada vez más interesado en las pequeñas y medianas empresas (de ahora en adelante PYMES), encuentra dificultades en la obtención de información que permita saber la situación de las microempresas en cuanto a su número, conformación sectorial e importancia económica. Fortaleciendo este criterio, según establece Dini \& Stumpo (2020), la ausencia de mercado común y de una real integración económica en la región que imposibilita un acuerdo sobre lo que es o no es una PYMES. No obstante, los mismos autores señalan que algunos de los aspectos fundamentales que caracterizan a este sector es su heterogeneidad, situación de informalidad, poca accesibilidad a financiamiento, limitado capital humano y carencia de exigencias técnicas.

A pesar de ello, las PYMES a nivel de Latinoamérica son el principal actor de la estructura del mercado, pues su aporte al crecimiento económico de la región es un factor de considerable peso y el número de puestos de trabajo que generan son la base con la que subsisten varias familias. Solamente en Ecuador, durante el periodo 2021, se llegaron a categorizar bajo código catastral del Servicio de Rentas Internas (SRI) un total de 1,003,287 microempresas, de las cuales, según la subsecretaria de calidad e inocuidad, un total de 1.362 corresponden al sector camaronero. Así mismo, según código catastral del SRI se logran determinar en la provincia de El Oro un total de 33,141 microempresas, representando estas el $3.30 \%$ del total a nivel nacional.

Ahora bien, el sector microempresarial ha venido incurriendo en varios inconvenientes a lo largo de los años, por una parte, según señala Rodríguez et al. (2019), los mismos no planifican de manera formal sus actividades, son ineficientes en el modo de comercializar sus productos o servicios, mantienen fuertes dificultades financieras y varios de sus integrantes sostienen amplios vacíos de conocimientos que les impiden aplicar técnicas que mejoren la eficiencia de la empresa; en este último aspecto, la escasez de conocimientos en lo productivo y comercial, aumenta la vulnerabilidad empresarial, dificultando el proceso de toma de decisiones, y por ende, incrementando el riesgo de absorción por el pobre manejo de sus finanzas en general.

Desde otro punto de vista, las expectativas de los microempresarios superan lo que la realidad puede efectivamente deparar, pues se subestima el nivel de control y planificación empresarial desde enfoques de gestión administrativos operativos y financieros. Teniendo en cuenta ello, Molina et al. (2016) señala que "en relación a la falta de planes estratégicos y/o operativos, el empresario no ha cambiado su forma tradicional de administrar la empresa, pues ha basado su toma de decisiones prácticamente en la intuición y experiencia".

Ante esta divulgación, Gamez et al. (2018) concluyen que "para las pymes latinoamericanas, se presenta otra problemática la cual es la ausencia de instrumentos y controles adecuados para la toma de decisiones, lo que no permite realizar una planeación financiera pertinente". Y por si fuese poco, la situación se ha visto agravada con los efectos de la emergencia sanitaria producto del Covid-19, ante este contexto, todos los sectores comerciales del país se han visto perjudicados por una consecuente crisis económica que afecta al comercio exterior por una caída en sus 
importaciones y exportaciones; haciendo hincapié en aquellos sectores productivos, como lo son principalmente las empacadoras, florícolas y camaroneras.

Concretamente, la industria camaronera ecuatoriana es una de las más golpeadas, ya que según determina Paladines et al. (2020), el sector camaronero previo a la pandemia presentaba un crecimiento en las exportaciones del $7.6 \%$, los cuales posicionaban al camarón ecuatoriano como el principal producto de exportación. Con el cierre de las fronteras, el sector descendió su nivel de exportación y producción en un $21 \%$.

Es plausible señalar así, que las empresas dedicadas a esta actividad (y en especial las PYMES) necesitan disponer de instrumentos que las ayuden a enfrentarse a esta abrupta realidad; es indispensable entonces que el microempresario orense cuente con herramientas de gestión que le sean de ayuda a la administración en el logro de sus objetivos en la línea de comercialización, innovación, recursos humanos, productividad, crecimiento, rentabilidad, entre otros; contribuyendo al crecimiento de la industria a través de una óptima planificación que repercuta de forma directa en el enfoque de gestión administrativa con impacto en la toma de decisiones.

En esta medida, varios autores recalcan las ventajas que ofrecen a las microempresas la implementación herramientas de planificación; por una parte, según explica Neciosup (2017) la planificación operativa como sistema de control sobre las actividades que la empresa debe seguir de forma programada, esta permite a la misma encaminarse en un plazo de tiempo al cumplimiento de sus metas y objetivos, a través del uso de presupuestos, indicadores y demás instrumentos de gestión.

De la mano de este, la planificación financiera en cambio garantiza el efecto financiero deseado a partir de la planeación operativa determinada, ya que según señala Pérez \& Pérez (2016) "la tarea de los directivos es la de alinear y comunicar a toda la organización la estrategia con la operación y, por ende, lograr que la cuantificación numérica propia de dicha planificación financiera refleje justamente esa coherencia".

Ante este análisis, la microempresa de producción camaronera Punta Diamante Pundiaman S.A. mantiene una limitada aplicación de estrategias de gestión enraizadas en la planificación operativa y financiera, dificultando la culminación de metas que permitan a la entidad desarrollarse competitivamente en la industria; ejecutando actividades sin un plan específico y dando lugar a un ineficiente uso de sus recursos. Es pertinente preguntarse si ¿la aplicación de la planificación operativa y financiera contribuirá a potenciar la gestión administrativa del microempresario en un mercado competitivo post covid-19?

Por tal razón, es de gran relevancia, destacar que la investigación será de utilidad para la empresa camaronera Punta Diamante Pundiaman S.A., debido a que direccionará su crecimiento comercial, y le permitirá aprovechar la información procesada por el sistema para tomar decisiones acertadas, que tenga prioridad sobre la protección de su capital y asegure el logro de sus metas, objetivos y estrategias. 
Considerando así mismo la importancia de este sector para el país y las dificultades que aún enfrenta, debido al crecimiento acelerado en su infraestructura tecnológica, la poca adaptabilidad y la falta de control a nivel operativo y financiero; la investigación tiene como objetivo elaborar una planificación operativa y financiera de la empresa Punta Diamante Pundiaman S.A. a través del presupuesto maestro y estrategias de gestión normadas, que contribuyan su gestión administrativa entre los periodos 2019 al 2022, reduciendo las posibilidades de errores y el fracaso empresarial.

En el levantamiento de la información fue necesario la implementación de encuestas a 416 microempresarios orenses enfocadas sobre las características de la empresa que inciden en una efectiva gestión administrativa; procesándose la información a través de un análisis de variables que da cuenta de la relación existente entre estas y los factores que explican un adecuado nivel de gestión administrativa, haciendo accesible la propuesta de herramientas de planificación.

De allí la importancia de la propuesta de instrumentos de planificación económica, logrando un eficiente manejo de los recursos financieros de la empresa, dirigidos a cumplir las metas propuestas por la organización, contribuyendo al direccionamiento oportuno, generando sostenibilidad y sirviendo como referente teórico para otros autores, instituciones educativas y empresas productoras que puedan hacer uso de este material.

La estructura de este trabajo investigativo está alineado a cuatro apartados: en el primero la introducción del estudio, en el cual se desarrolla la problemática, objetivo, justificación e importancia del tema; el segundo detalla la metodología aplicada, así como las fuentes de información acudidas para el desarrollo del trabajo; el tercero presenta los resultados, en el cual se desarrolla el análisis de variables, en conjunto con las proyecciones estimadas basadas en históricos, proponiéndose un análisis del plan estratégico, cuya finalidad está enfocada en evaluar factores críticos que permitan la propuesta de estrategias efectivas en responder a las necesidades de la empresa; y el último apartado que concentra las conclusiones obtenidas tras la revisión de los resultados que respondan a la teoría planteada.

\section{Metodología}

Este trabajo de investigación aplicó una metodología de carácter correlacional, analítico y descriptivo; pues se hace uso del programa SPSS 21.0 para determinar el grado de asociación estadística entre las características de la empresa que revelan su nivel de gestión administrativa, con ello identificando la necesidad de las microempresas orenses de aplicar herramientas financieras y proponiendo un modelo gerencial con el uso de instrumentos de planificación estratégica, operativa y financiera (Hernández et al., 2014).

Así también, la investigación fue de tipo no experimental, pues no se llegó a modificar la información obtenida; y de corte longitudinal, debido a que se extrajeron, procesaron y analizaron los datos operativos y financieros de la empresa para una proyección de 3 periodos (Oranday et al., 2019).

Finalmente, los resultados obtenidos se basan en el levantamiento de información de 416 encuestas aplicadas a microempresarios orenses que participan en los proyectos de investigación 
de "Herramientas financieras, direccionado al fortalecimiento y desarrollo de las microempresas en la Provincia de EI Oro" y el proyecto de vinculación de "Asesoría tributaria gratuita mediante NAF" de la Universidad Metropolitana del Ecuador sede Machala, con inclinación a identificar las características de las empresas que tienen una mayor incidencia sobre la efectiva gestión administrativa; entre las preguntas realizadas están: edad del microempresario, nivel de instrucción, la estructura de sus activos, pasivos, ingresos y egreso anuales; tiempo en la actividad económica, si lleva o no un control de sus operaciones diarias, tipos de registros de datos utilizados como herramientas de gestión, instrumentos financieros utilizadas para la toma de decisiones y si son aplicadas o no políticas y acciones reglamentarias para una efectiva gestión tributaria.

A través del análisis de estas variables, se muestre la relación existente entre éstas y los cinco factores que influyen en la dirección administrativa, haciendo accesible la propuesta de investigación.

\section{Resultados}

\subsection{Análisis de variables sobre la buena gestión administrativa de la microempresa}

\section{orense}

El presente estudio comenzó con el análisis de la Tabla 1, la prueba de suficiencia muestral aplicada para la evaluación de la pertinencia del análisis de factores. En general, una mayor medida de adecuación muestral de Kaiser-Meyer-Olkin conlleva una mayor robustez en la solución, lo óptimo es que el valor de la cifra sea: MASg $\geq 0,5$. Considerándose que para el presente estudio las respuestas del $\mathrm{KMO}$ es igual a 0,784, se valida la pertinencia del análisis de factores a llevar a cabo.

Las tablas que se presentan a continuación fueron elaboración propia a partir de la base de datos de los proyectos de la UMET (SPSS Ver. 21.0).

Tabla 1.

Prueba de suficiente muestral KMO

\begin{tabular}{|c|c|c|}
\hline \multicolumn{2}{|c|}{ Medida de adecuación muestral de Kaiser-Meyer-Olkin. } & ,784 \\
\hline \multirow[t]{3}{*}{ Prueba de esfericidad de Bartlett } & Chi-cuadrado aproximado & 1193,640 \\
\hline & Gl (grados de libertad) & 55 \\
\hline & Sig. (nivel de significancia) & ,000 \\
\hline
\end{tabular}

A continuación, la Tabla 2 que deja ver la matriz de anti-imagen para las medidas de adecuación del muestreo, indicando en su diagonal principal que todas las variables (las preguntas de las encuestas aplicadas) son pertinentes para el análisis de factores, debido a que los coeficientes de correlación presentan valores encima del 0,5. 
Tabla 2.

Matriz anti-imagen para medidas de adecuación de muestreo

\begin{tabular}{|c|c|c|c|c|c|c|c|c|c|c|c|c|}
\hline & & ?ृ & 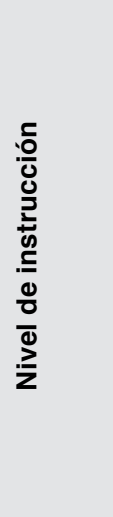 & 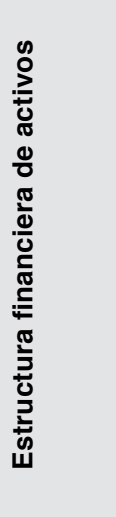 & 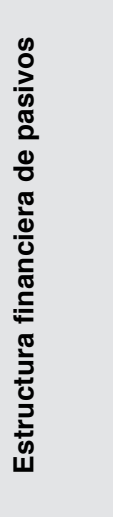 & 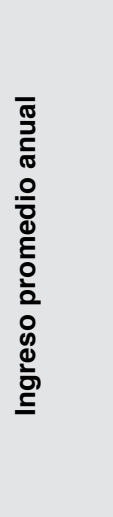 & 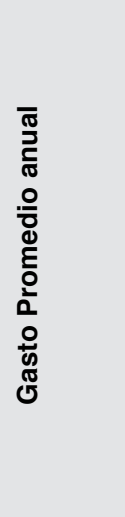 & 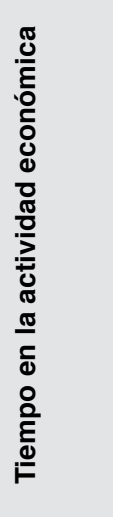 & 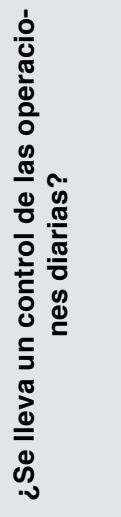 & 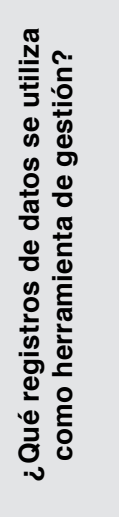 & 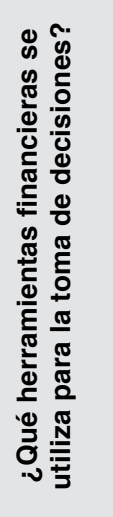 & 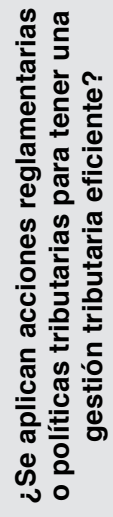 \\
\hline \multirow{11}{*}{ 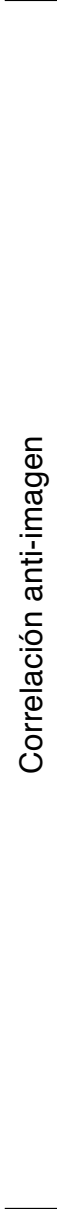 } & Edad &, $666^{a}$ & ,154 &,- 048 & ,055 &,- 114 &,- 040 &,- 384 &,- 060 & ,056 &,- 037 & ,026 \\
\hline & $\begin{array}{c}\text { Nivel de } \\
\text { instrucción }\end{array}$ & ,154 &, $735^{a}$ &,- 008 &,- 137 &,- 137 & ,110 & ,043 & ,113 &,- 160 & , 100 & ,066 \\
\hline & $\begin{array}{l}\text { Estructura } \\
\text { financiera de } \\
\text { activos }\end{array}$ &,- 048 &,- 008 &, $820^{a}$ &,- 470 &,- 142 &,- 131 &,- 117 & ,006 & ,039 & ,142 & ,034 \\
\hline & $\begin{array}{c}\text { Estructura } \\
\text { financiera de } \\
\text { pasivos }\end{array}$ & ,055 &,- 137 &,- 470 &, $803^{a}$ &,- 012 &,- 168 &,- 090 & ,038 &,- 040 &,- 026 & ,036 \\
\hline & $\begin{array}{c}\text { Ingreso } \\
\text { promedio anual }\end{array}$ &,- 114 &,- 137 &,- 142 &,- 012 &, $785^{a}$ &,- 520 &,- 018 &,- 035 & ,020 & ,120 & ,076 \\
\hline & $\begin{array}{c}\text { Egreso } \\
\text { promedio anual }\end{array}$ &,- 040 & ,110 &,- 131 &,- 168 &,- 520 &, $778^{a}$ &,- 049 &,- 001 &,- 077 &,- 031 & ,007 \\
\hline & $\begin{array}{l}\text { Tiempo en } \\
\text { la actividad } \\
\text { económica }\end{array}$ &,- 384 & ,043 &,- 117 &,- 090 &,- 018 &,- 049 &, $781^{a}$ & ,064 &,- 163 & ,051 & ,032 \\
\hline & $\begin{array}{l}\text { ¿Se lleva un } \\
\text { control de las } \\
\text { operaciones } \\
\text { diarias? }\end{array}$ &,- 060 & ,113 & ,006 & ,038 &,- 035 &,- 001 &, 064 &, $765^{a}$ &,- 044 &,- 244 &,- 305 \\
\hline & $\begin{array}{l}\text { ¿Qué registros } \\
\text { de datos se } \\
\text { utiliza como } \\
\text { herramienta de } \\
\text { gestión? }\end{array}$ & ,056 &,- 160 & ,039 &,- 040 & ,020 &,- 077 &,- 163 &,- 044 &, $609^{a}$ &,- 106 & ,107 \\
\hline & $\begin{array}{c}\text { ¿Qué } \\
\text { herramientas } \\
\text { financieras se } \\
\text { utiliza para } \\
\text { la toma de } \\
\text { decisiones? }\end{array}$ &,- 037 & , 100 & ,142 &,- 026 & ,120 &,- 031 &, 051 &,- 244 &,- 106 &, $817^{a}$ &,- 210 \\
\hline & $\begin{array}{l}\text { ¿Se aplican } \\
\text { acciones } \\
\text { reglamentarias } \\
\text { o políticas } \\
\text { tributarias } \\
\text { para tener } \\
\text { una gestión } \\
\text { tributaria } \\
\text { eficiente? }\end{array}$ & ,026 & ,066 & ,034 & ,036 & ,076 & ,007 & ,032 &,- 305 & ,107 &,- 210 &, $824^{a}$ \\
\hline
\end{tabular}

a. Determinante $=, 055$

Por otra parte, la Tabla 3 presenta la matriz de comunalidades, la cual detalla el porcentaje de varianza de cada una de las variables que son explicadas por los factores, lo ideal para el estudio es que el valor de extracción de cada una de las variables sea superior a 0,5. En este caso, cada 
una de las mismas cumplen con el requisito limitante, con lo cual se procede con el análisis de factores.

Tabla 3.

Matriz de comunalidades

\begin{tabular}{ccc}
\hline & Inicial & Extracción \\
\hline Edad & 1,000 &, 729 \\
\hline Nivel de instrucción & 1,000 &, 647 \\
\hline Estructura financiera de pasivos & 1,000 &, 738 \\
\hline Ingreso promedio anual & 1,000 &, 753 \\
\hline Egreso promedio anual & 1,000 &, 779 \\
\hline Tiempo en la actividad económica & 1,000 &, 815 \\
\hline ¿Se lleva un control de las operaciones diarias? & 1,000 &, 752 \\
\hline ¿Qué registros de datos se utiliza como herramienta de gestión? & 1,000 &, 656 \\
\hline ¿QQe he herramientas financieras se utiliza para la toma de decisiones? & 1,000 &, 906 \\
\hline Método de extracción: Análisis de Componentes principales. & 1,000 &, 609 \\
\hline
\end{tabular}

A continuación, en la Tabla 4 se demuestra como los cinco factores considerados para el análisis explican el $73,139 \%$ de la varianza total de las variables estudiadas, siendo el mismo un porcentaje considerado como "Aceptable". El primer factor considerado explica el 17,511\% de esta, el factor 2 el 17,508\%, el factor 3 el 14,153\%, el factor 4 el 14,025\% y el factor 5 el 9,942\%. 
Tabla 4.

Varianza total de las variables sujetas a estudio explicada por los factores

\begin{tabular}{|c|c|c|c|c|c|c|c|c|c|}
\hline \multirow[t]{2}{*}{ Factores } & \multicolumn{3}{|c|}{ Autovalores iniciales } & \multicolumn{3}{|c|}{$\begin{array}{l}\text { Sumas de las saturaciones al } \\
\text { cuadrado de la extracción }\end{array}$} & \multicolumn{3}{|c|}{$\begin{array}{l}\text { Suma de las saturaciones al } \\
\text { cuadrado de la rotación }\end{array}$} \\
\hline & Total & $\begin{array}{c}\% \text { de la } \\
\text { varianza }\end{array}$ & $\begin{array}{l}\% \text { acu- } \\
\text { mulado }\end{array}$ & Total & $\begin{array}{c}\% \text { de la } \\
\text { varianza }\end{array}$ & $\begin{array}{l}\% \text { acu- } \\
\text { mulado }\end{array}$ & Total & $\begin{array}{c}\% \text { de la } \\
\text { varianza }\end{array}$ & $\begin{array}{l}\% \text { acu- } \\
\text { mulado }\end{array}$ \\
\hline 1 & 3,569 & 32,441 & 32,441 & 3,569 & 32,441 & 32,441 & 1,926 & 17,511 & 17,511 \\
\hline 2 & 1,591 & 14,461 & 46,902 & 1,591 & 14,461 & 46,902 & 1,926 & 17,508 & 35,019 \\
\hline 3 & 1,110 & 10,092 & 56,994 & 1,110 & 10,092 & 56,994 & 1,557 & 14,153 & 49,172 \\
\hline 4 & 1,036 & 9,418 & 66,412 & 1,036 & 9,418 & 66,412 & 1,543 & 14,025 & 63,197 \\
\hline 5 & ,740 & 6,727 & 73,139 & ,740 & 6,727 & 73,139 & 1,094 & 9,942 & 73,139 \\
\hline 6 & ,692 & 6,292 & 79,431 & & & & & & \\
\hline 7 & ,582 & 5,289 & 84,720 & & & & & & \\
\hline 8 &, 546 & 4,960 & 89,680 & & & & & & \\
\hline 9 & ,478 & 4,345 & 94,025 & & & & & & \\
\hline \multirow[t]{2}{*}{10} & ,348 & 3,160 & 97,185 & & & & & & \\
\hline & $\begin{array}{c}11 \\
, 310 \\
2,815\end{array}$ & & 100,000 & & & & & & \\
\hline
\end{tabular}

Por último, la Tabla 5 da cuenta de las variables que son explicadas por los cinco factores considerados. En este caso, la variable de control sobre las operaciones de la empresa, el tipo de herramientas financieras utilizadas para la toma de decisiones y la aplicación de acciones reglamentarias y políticas tributarias son explicadas por el factor 1 ; las variables relacionadas con el nivel de ingresos y egresos anuales se interpretan por el facto 2; las variables de nivel de instrucción, activos y pasivos se comprender por el factor 3 ; las variables edad y tiempo en la actividad económica se examinan por el factor 4; y por último el factor 5 describe los tipos de herramientas para el control administrativo. 
Tabla 5.

Matriz de componentes rotados

\begin{tabular}{|c|c|c|c|c|c|}
\hline & & & Facto & & \\
\hline & 1 & 2 & 3 & 4 & 5 \\
\hline Edad & & & & 831 & \\
\hline Nivel de instrucción & & & 605 & & \\
\hline Estructura financiera de activos & & & ,649 & & \\
\hline Estructura financiera de pasivos & & & ,761 & & \\
\hline Ingreso promedio anual & & ,831 & & & \\
\hline Egreso promedio anual & & ,868 & & & \\
\hline Tiempo en la actividad económica & & & & ,791 & \\
\hline ¿Se lleva un control de las operaciones diarias? & ,799 & & & & \\
\hline $\begin{array}{l}\text { ¿Qué registros de datos se utiliza como herramienta de } \\
\text { gestión? }\end{array}$ & & & & & ,943 \\
\hline $\begin{array}{l}\text { ¿Qué herramientas financieras se utiliza para la toma de } \\
\text { decisiones? }\end{array}$ & ,719 & & & & \\
\hline $\begin{array}{l}\text { ¿Se aplican acciones reglamentarias o políticas tributarias para } \\
\text { tener una gestión tributaria eficiente? }\end{array}$ & ,758 & & & & \\
\hline Método de extracción: Análisis de componentes principales. & & & & & \\
\hline Método de rotación: Normalización Varimax con Kaiser. ${ }^{a}$ & & & & & \\
\hline a. La rotación ha convergido en 7 iteraciones. & & & & & \\
\hline
\end{tabular}

Estableciéndose la relación entre la presencia de instrumentos de control operativo y financiero de la empresa, a través de factores que explican diversas variables, siendo las de mayor relevancia para el estudio: el control de operaciones diarias, la utilización de herramientas de gestión, la ejecución de herramientas financieras para la toma de decisiones y la aplicación de acciones reglamentarias o políticas tributarias; mismas que tienen incidencia sobre una efectiva gestión administrativa, se procede a presentar una propuesta de herramientas operativas y financieras que solventen las carencias de control de las microempresas camaroneras, a través del estudio de caso de la microempresa Camaronera Punta Diamante Pundiaman S.A.

\subsection{Propuesta de plan estratégico para la microempresa Camaronera Punta Diamante}




\section{Pundiaman S.A.}

Para el correcto desarrollo del plan estratégico a llevar a cabo, fue necesario la formulación de la descripción de la empresa, en conjunto con la filosofía de la misma, reflejada en su misión, visión, valores y código de ética planteados; para ello la Tabla 6 presenta la siguiente información.

\section{A continuación, las siguiente Tablas y Figuras fueron elaboración propia, a partir de la base de datos de la Superintendencia de Compañías, Valores y Seguros}

Tabla 6.

Planteamiento filosófico de la microempresa camaronera Punta Diamante Pundiaman S.A.

\section{Descripción de la empresa}

La sociedad acuícola Punta Diamante Pundiaman S.A. es una industria Camaronera que se ha dedicado a explotación de criaderos de camarones (camaroneras) y criaderos de larvas de camarón (laboratorios de larvas de camarón). Sus productos han llamado la atención del consumidor y respectivos compradores, pues nos presentan a gran plenitud su producto, en comparación a los demás por su gran tamaño y precio. Punta Diamante Pundiaman S.A. nació en el 2016 y lleva 4 años de vida en el mercado, siendo una de las empresas camaroneras más productivas en la provincia El Oro, su sucursal se ubica en Machala, El Oro, segunda Diagonal S/N y Circunvalación Sur, sin embargo, las piscinas que emplea para la producción, junto con el resto de su equipo y personal de campo se encuentran en la isla Mondragón

\begin{tabular}{ll}
\hline Misión & La empresa Punta Diamante Pundiaman S.A. se dedica a explotación de criaderos de camarones, \\
& criaderos de larvas de camarón; con la capacidad de cumplir con los requisitos implícitos y explícitos \\
& de nuestros clientes, a través de técnicas adecuadas de control de calidad, procesos y trazabilidad, que \\
& aseguran la inocuidad de nuestros productos. \\
\hline Visión & La empresa Punta Diamante Pundiaman S.A. planea lograr una posición de liderazgo en la \\
& exportación de camarón del Ecuador, con base en un proceso eficiente y seguro, a través de personal \\
& bien capacitado, he innovando continuamente con la implementación de técnicas que mejoren la \\
& productividad y permitan cumplir con los requisitos legales del sector, satisfaciendo las expectativas de \\
& calidad de nuestros clientes.
\end{tabular}

Valores de la empresa

Excelencia: La calidad llevada al máximo, eso es la excelencia, la empresa Punta Diamante Pundiaman S.A. siempre exige lo mejor, para dar lo mejor; que el cliente y empleado vean que les ofrecemos algo de excelencia les impulsará a quedarse con nosotros.

Responsabilidad: Tanto en la vertiente social como en la ecológica, la empresa Punta Diamante Pundiaman S.A. ofrece demostrar ser responsables con la sociedad y el medio ambiente, haciendo ver que no se interesa únicamente por los beneficios económicos.

Transparencia: En un entorno social donde cada vez es menos frecuente ofrecer los medios para comprobar la legitimidad de la información, es necesario que un factor clave del desenvolvimiento normal de la institución se rija por medio de la transparencia hacia el equipo y los clientes. Nuestra empresa implica confianza y las relaciones humanas, incluidas las comerciales, se forjan en base a este valor.

Competitividad: La competitividad empresarial le permite a nuestra organización buscar nuevas formas de innovar para mantenerse en pie y alcanzar los objetivos propuestos, por decirlo de un modo, la búsqueda de la subsistencia es la base para el crecimiento de la industria.

Constancia: La empresa Punta Diamante Pundiaman S.A. inculca a nuestros empleados el valor del trabajo duro y de la constancia. Asimismo, los empleados deben ver que su persistencia en cumplir un buen trabajo se ve reflejada en resultados, que redundan en beneficios tanto personales como para la empresa. 


\section{Código de ética}

En relación con Realizar un ejercicio profesional, ético y responsable de sus actividades diarias. las funciones de dirección

Cumplir y hacer cumplir el código ético a través de su comunicación a la hora de ingreso.

Mantener los libros y registros contables de la empresa fieles a la realidad de su desempeño.

Facilitar a los auditores externos e internos de la empresa toda la información y explicaciones que requieran en el ejercicio de su actividad.

Cada integrante deberá de comunicar inmediatamente a la administración cualquier hecho o situación que pudiera ocasionar un conflicto a la empresa.

Hacer frente al pago de deudas y obligaciones financieras de la empresa.

El mérito del empleado prevalecerá como factor clave en la asignación de sus derechos y obligaciones.

En relación No abusar de una posición privilegiada en el mercado.

con los

competidores

Competir lealmente con otras empresas camaroneras del sector.

Procurar la cooperación con otras instituciones del mercado, basada esta ayuda en el respeto mutuo entre competidores.

No captar clientes de otros competidores mediante técnicas poco éticas.

En relación con Tratar con dignidad, respeto y justicia a los empleados sin distinción de su rango.

los empleados

No se aceptará ningún tipo de discriminación por razón de raza, religión, edad, nacionalidad, sexo o cualquier otra condición personal o social ajena a sus condiciones de mérito y capacidad dentro y fuera de la institución.

No se permitirá ninguna forma de violencia, acoso o abuso con algún miembro de la empresa en el desempeño de sus funciones.

Establecer reglas de contratación que concuerden con los derechos de la empresa y empleados.

Garantizar la seguridad e higiene en el trabajo, adoptando las medidas de precaución necesarias para que en la práctica de sus labores puedan desenvolverse en un ambiente digno.

En relación con Tener una estrecha relación con proveedores directos e indirectos de materiales, siempre manteniendo los proveedores la relación en las normas de ética y legalidad de la empresa.

y clientes

Buscar y seleccionar únicamente proveedores cuyos procesos productivos sean transparentes, responsables, genuinos y realizados conforme los estatutos que rige el Ecuador.

Seleccionar a proveedores de acuerdo a la calidad de sus productos, precio, así como flexibilidad en las condiciones de entrega y pago.

La propuesta del planteamiento filosófico del negocio es el punto de partida sobre el cual se debe desarrollar el plan estratégico, pues estos elementos orientan el curso de acción de la empresa y permiten la formulación de objetivos estratégicos y, en consecuencia, la construcción de matrices para la selección de estrategias a implementarse en vistas a cumplir tales objetivos (Amaguaña et al., 2017).

Tras la culminación de este planteamiento, se presenta en la Tabla 7 las debilidades, oportunidades, fortalezas y amenazas derivados de los resultados obtenidos en el análisis interno y externo para la empresa Punta Diamante Pundiaman S.A. Las mismas se tienen en cuenta para el desarrollo de cuatro estrategias tipo DO, FO, DA y FA, cada una de las cuales considera los factores que engloban para su propuesta. 
Tabla 7.

Matriz FODA de la empresa Punta Diamante Pundiaman S.A.

\section{Debilidades}

Deficiencia en la implementación de buenas prácticas acuícolas.

No existen informes u otros registros físicos o en digital sobre pagos vencidos.

La empresa no aprovecha sus oportunidades de financiamiento como debería.

Altos precios de larva en el mercado.

\section{Oportunidades}

Proveedores normalmente otorgan crédito a insumos.

Posesión de extensas tierras fértiles para la producción de camarón.

Continuo desarrollo de nuevas tecnologías para la producción.

Alta demanda de camarón a nivel internacional.

\section{Amenazas}

Difícil acceso a servicios básicos.

Proveedores de semilla de camarón inestables.

Inseguridad en la Isla Mondragón.

Enfermedades del camarón.

\section{Estrategia - DO}

Solicitar créditos a proveedores de insumos, donde se le permita a la empresa a pagar en cómodas cuotas durante la duración de la corrida, debido a los altos precios del mercado.

Capacitar al personal para que estén aptos en la aplicación de tecnologías actuales para la producción acuícola.

Desarrollar un manual de procedimientos para las cuentas por cobrar de la entidad, que complemente al control realizado por el SI.

Aprovechar las oportunidades de financiamiento que se le ofrecen a la empresa, para obtener una mayor producción de calidad.

Estrategia - DA

Diseñar sistema de capacitación que ayude a la entidad a implementar buenas prácticas acuícolas.

Mantener una reserva de agua potable vinculado a un sistema de cisternas en cumplimiento de buenas prácticas acuícolas.

Establecer una alianza que posibilite trabajar de forma directa con proveedores de semillas.

Proporcionar el tratamiento necesario a las piscinas para disminuir la morbilidad y mortalidad del camarón, evitando con ello mayores costos en su adquisición.

\section{Fortalezas}

Existencia de fuentes de financiamiento para la producción camaronera.

Las instalaciones se mantienen limpias y saludables.

Presencia de instalaciones de bombeo.

Se vende de forma directa el camarón a exportadores.

\section{Estrategia - FO}

Fortalecer relaciones con proveedores para no depender de financiamiento de terceros.

Mantener un nivel productivo adecuado en base al uso de nuevas tecnologías, que permita exportar al extranjero.

Producir un camarón de calidad, cumpliendo todas las medidas de bioseguridad y limpieza para resultar más atractivo en el mercado.

Aprovechar y salvaguardar la fertilidad del suelo para la producción de un camarón de mayor calidad.

\section{Estrategia - FA}

Implementar progresivamente servicios básicos en la isla, apoyándose esto en fuentes de financiación externa.

Ampliar las rutas de distribución del producto a exportadores para disminuir riesgos por inseguridad en la isla.

Potenciar las políticas de limpieza y control sanitario para evitar enfermedades en el camarón.

Establecer lazos con entidades bancarias para obtener financiamiento y con ello invertir o gestionar un mejor acceso en los servicios básicos.

De acuerdo a Chávez (2016), el análisis FODA sirve como herramienta de diagnóstico situacional y es el punto de partida para la elaboración de estrategias, pues el éxito de su implementación depende del análisis del entorno interno y externo que se haya realizado.

\section{En el desarrollo de la matriz propuesta, no solamente se tienen en cuenta las ventajas y} desventajas de la organización, sino que se consideró el efecto de cada uno de estos factores en la actividad de la empresa, para la propuesta de estrategias de acción a sobre los cuales la gerencia podrán optar para potenciar el desarrollo de su empresa; en este aspecto, "el análisis 
de la matriz FODA, es necesario dentro de las organizaciones para ayudar a obtener resultados importantes para el desarrollo competitivo" (Pibaque et al., 2020, p. 43).

Posteriormente, en la Tabla 8 se tiene la matriz PEYEA de la empresa, en el desarrollo de la misma se determina y califica cada una de las fuerzas que interactúan en la empresa, tanto por parte del campo financiero, estabilidad en el ambiente, ventaja competitiva y fuerzas de la industria.

Tabla 8.

Matriz PEYEA de la empresa Punta Diamante Pundiaman S.A.

\begin{tabular}{cccc}
\hline \multicolumn{2}{c}{ Posición Estratégica Intenta } & \multicolumn{2}{c}{ Posición Estratégica Externa } \\
\hline Fuerza Financiera (FF) & Calif. & Estabilidad del Ambiente (EA) & Calif. \\
\hline Rentabilidad & 2 & Variabilidad de la demanda & -4 \\
\hline Deudas a Corto Plazo & 2 & Presión Competitiva & -2 \\
\hline Acceso a Crédito & 6 & Elasticidad de la demanda & -5 \\
\hline Suma & 10 & Suma & -11 \\
\hline Promedio & 3,33 & Promedio & -3.67 \\
\hline Ventaja Competitiva (VC) & Calif. & Fuerzas de la Industria (FI) & Calif. \\
\hline Calidad del Producto & -2 & Estabilidad Financiera & 6 \\
\hline Lealtad de los Clientes & -2 & Conocimientos Tecnológicos & 4 \\
\hline Participación en el & -4 & Facilidad para entrar al & 3 \\
mercado & & mercado & \\
\hline Suma & -8 & Suma & 13 \\
\hline Promedio & $-2,67$ & Promedio & 4,33 \\
\hline Vector $X$ & 1,67 & & \\
\hline Vector $Y$ & $-0,33$ & &
\end{tabular}

Con los resultados de la matriz, se obtiene en conjunto la Figura 1, en la cual se aprecia que la organización debe de implementar estrategias competitivas. Puesto que con respecto a los valores obtenidos en los factores individuales que componen las 4 fuerzas analizadas, se tiene que:

- La fuerza financiera (FF) obtuvo un puntaje de 3,33

- El ítem fuerza de la industria (FI) registró un puntaje de 4,33

- La estabilidad del ambiente (EA) otorgo un puntaje de -3,67

- La ventaja competitiva (VC) presentó un total de -2,67.

Al realizar las sumatorias necesarias, se calculó que el eje $X$ tendrá un valor de 1,67 mientras que Y será de $-0,33$. En base a ello, se deduce que las tendencias de las estrategias en la camaronera deberán ser de tipo competitivo, debido a que el vector se encuentra en dicho cuadrante. Por lo mismo, lo más conveniente será aplicar estrategias de penetración en el mercado, las cuales apuntan a incrementar el volumen de ventas dentro del sector en el que opera la entidad, el objetivo será entonces, llegar a más consumidores y aumentar el número de clientes potenciales. 
Con la aplicación de este tipo de estrategia se desea conducir a la empresa a un aumento en sus indicadores de rentabilidad y los niveles de competitividad.

Figura 1.

Gráfico de resultados de la matriz PEYEA

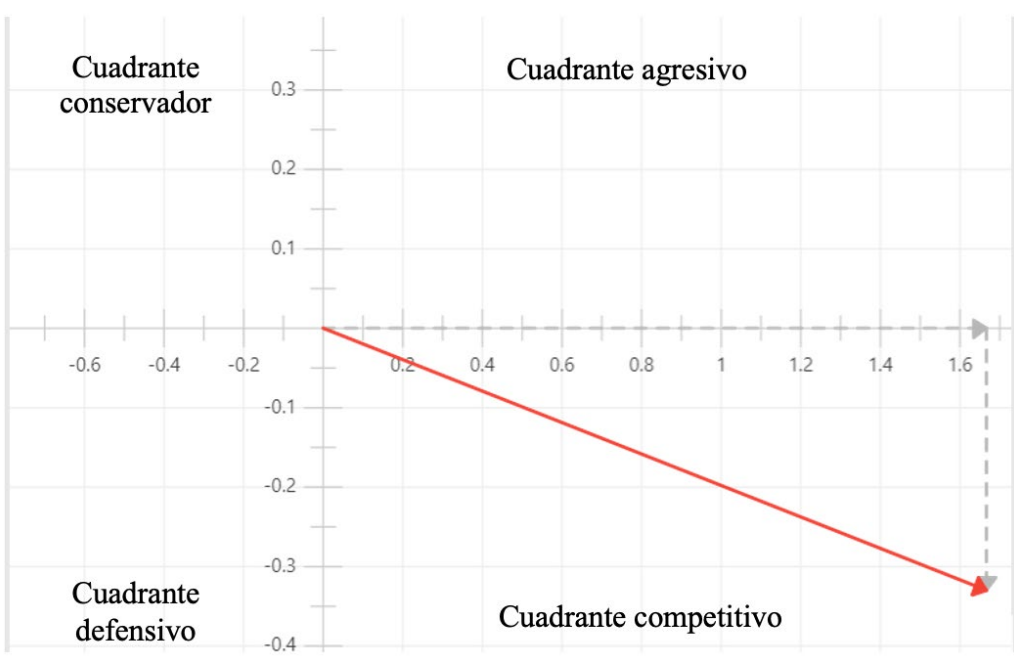

Finalmente, en la Tabla 9 se exponen los resultados de la matriz MPECC, en la cual en base al TCA calculado para cada una de las cuatro estrategias escogidas, se tiene que la prioridad en la que es necesario aplicar cada una de estas responde a:

1. Estrategia 1 (con un valor de 4): establecer lazos con entidades bancarias para obtener financiamiento y con ello invertir o gestionar un mejor acceso en los servicios básicos.

2. Estrategia 2 (con un valor de 3,8): implementar progresivamente servicios básicos en la isla, apoyándose esto en fuentes de financiación externa.

3. Estrategia 3 (con un valor de 3,5): desarrollar un manual de procedimientos para las cuentas por cobrar de la entidad, que complemente al control realizado por el SI.

4. Estrategia 4 (con un valor de 3,1 ): potenciar las políticas de limpieza y control sanitario para evitar enfermedades en el camarón. 
Tabla 9.

Matriz MPEC de la empresa Punta Diamante Pundiaman S.A.

\begin{tabular}{|c|c|c|c|c|c|c|c|c|c|}
\hline \multirow{3}{*}{$\begin{array}{l}\text { Factores críticos para } \\
\text { el éxito } \\
\text { Oportunidades }\end{array}$} & \multicolumn{9}{|c|}{ Alternativa estratégica } \\
\hline & \multirow[b]{2}{*}{ Peso } & \multicolumn{2}{|c|}{$\begin{array}{c}\text { Desarrollar } \\
\text { un manual de } \\
\text { procedimientos } \\
\text { para las cuentas } \\
\text { por cobrar de } \\
\text { la entidad, que } \\
\text { complemente al } \\
\text { control realizado } \\
\text { por el SI }\end{array}$} & \multicolumn{2}{|c|}{$\begin{array}{l}\text { Implementar pro- } \\
\text { gresivamente ser- } \\
\text { vicios básicos en } \\
\text { la isla, apoyándo- } \\
\text { se esto en fuentes } \\
\text { de financiación } \\
\text { externa }\end{array}$} & \multicolumn{2}{|c|}{$\begin{array}{l}\text { Potenciar las po- } \\
\text { líticas de limpieza } \\
\text { y control sani- } \\
\text { tario para evitar } \\
\text { enfermedades en } \\
\text { el camarón }\end{array}$} & \multicolumn{2}{|c|}{$\begin{array}{l}\text { Establecer lazos } \\
\text { con entidades ban- } \\
\text { carias para obtener } \\
\text { financiamiento y } \\
\text { con ello invertir o } \\
\text { gestionar un mejor } \\
\text { acceso en los servi- } \\
\text { cios básicos }\end{array}$} \\
\hline & & $\mathrm{CA}$ & TCA & $\mathrm{CA}$ & TCA & $\mathrm{CA}$ & TCA & $\mathrm{CA}$ & TCA \\
\hline $\begin{array}{c}\text { Proveedores } \\
\text { normalmente otorgan } \\
\text { créditos a insumos }\end{array}$ & 0,1 & 4 & 0,4 & 2 & 0,2 & 1 & 0,1 & 2 & 0,2 \\
\hline $\begin{array}{l}\text { Posesión de extensas } \\
\text { tierras fértiles para la } \\
\text { producción de camarón }\end{array}$ & 0,2 & 1 & 0,2 & 1 & 0,1 & 1 & 0,1 & 2 & 0,2 \\
\hline $\begin{array}{l}\text { Continuo Desarrollo de } \\
\text { Nuevas Tecnologías para } \\
\text { la Producción }\end{array}$ & 0,1 & 3 & 0,3 & 3 & 0,3 & 3 & 0,3 & 3 & 0,3 \\
\hline $\begin{array}{l}\text { Alta demanda de } \\
\text { camarón a nivel } \\
\text { internacional }\end{array}$ & 0,1 & 1 & 0,1 & 1 & 0,1 & 1 & 0,1 & 1 & 0,1 \\
\hline \multicolumn{10}{|l|}{ Amenazas } \\
\hline $\begin{array}{c}\text { Difícil acceso a servicios } \\
\text { básicos } \\
\end{array}$ & 0,2 & 1 & 0,2 & 4 & 0,4 & 2 & 0,2 & 4 & 0,4 \\
\hline $\begin{array}{l}\text { Proveedores de semillas } \\
\text { de camarón inestables }\end{array}$ & 0,1 & 1 & 0,1 & 1 & 0,1 & 1 & 0,1 & 1 & 0,1 \\
\hline $\begin{array}{l}\text { Inseguridad en la Isla } \\
\text { Mondragón }\end{array}$ & 0,1 & 3 & 0,3 & 2 & 0,2 & 2 & 0,2 & 2 & 0,2 \\
\hline $\begin{array}{l}\text { Enfermedades del } \\
\text { camarón }\end{array}$ & 0,1 & 1 & 0,1 & 3 & 0,3 & 4 & 0,4 & 3 & 0,3 \\
\hline \multicolumn{10}{|l|}{ Fortalezas } \\
\hline $\begin{array}{l}\text { Existencia de fuentes de } \\
\text { financiamiento para la } \\
\text { producción camaronera }\end{array}$ & 0,2 & 1 & 0,2 & 4 & 0,4 & 1 & 0,1 & 4 & 0,4 \\
\hline $\begin{array}{l}\text { Las instalaciones se } \\
\text { mantienen limpias y } \\
\text { saludables }\end{array}$ & 0,1 & 1 & 0,1 & 4 & 0,4 & 4 & 0,4 & 4 & 0,4 \\
\hline $\begin{array}{c}\text { Presencia de } \\
\text { instalaciones de bombeo. }\end{array}$ & 0,1 & 1 & 0,1 & 3 & 0,3 & 3 & 0,3 & 3 & 0,3 \\
\hline $\begin{array}{c}\text { Se vende de forma } \\
\text { directa el camarón a } \\
\text { exportadores }\end{array}$ & 0,1 & 1 & 0,1 & 1 & 0,1 & 1 & 0,1 & 1 & 0,1 \\
\hline Debilidades & & & & & & & & & \\
\hline
\end{tabular}




\begin{tabular}{|c|c|c|c|c|c|c|c|c|c|}
\hline $\begin{array}{c}\text { Deficiencia en la } \\
\text { implementación de } \\
\text { buenas prácticas } \\
\text { acuícolas }\end{array}$ & 0,1 & 4 & 0,4 & 3 & 0,3 & 4 & 0,4 & 4 & 0,4 \\
\hline $\begin{array}{l}\text { No existen informes u } \\
\text { otros registros físicos o } \\
\text { en digital sobre pagos } \\
\text { vencidos }\end{array}$ & 0,1 & 4 & 0,4 & 1 & 0,1 & 1 & 0,1 & 1 & 0,1 \\
\hline $\begin{array}{l}\text { Altos precios de larva en } \\
\text { el mercado }\end{array}$ & 0,1 & 1 & 0,1 & 1 & 0,1 & 1 & 0,1 & 1 & 0,1 \\
\hline
\end{tabular}

Las estrategias resultan para la empresa un instrumento útil para cumplir con los objetivos que la misma se ha propuesto, debido a que estas tienen en cuenta los factores internos y externos de mayor impacto en la organización; en definitiva, el punto clave de las estrategias es "lograr una ventaja en un entorno cambiante, mediante la configuración de sus recursos y competencias, con el fin de satisfacer las expectativas de las partes interesadas" (Rodríguez et al., 2020, p. 193).

No obstante, es necesario tener en mente que el mercado está en constante evolución y el sector camaronero no es la excepción, con lo cual, tal y como señala Espinoza et al. (2018) "la competencia, los clientes y mercado van cambiando día a día, por lo que los procesos, estrategias y objetivos de las empresas deben de irse modificando, según sea el panorama empresarial".

\subsection{Presupuesto maestro para la microempresa camaronera Punta Diamante Pundiaman}

S.A.

Una herramienta de planificación indispensable será el presupuesto maestro creado para la camaronera, el mismo se desarrolla en base a ciertas expectativas que se tengan sobre el posible desarrollo del negocio; para el caso de la microempresa Punta Diamante Pundiaman S.A. se consideraron los siguientes factores:

- La empresa ha invertido un total de $\$ 32.734,00$ en adquisición de nueva propiedad, planta y equipo (PPE).

- Debido a la inversión en PPE realizada, se proyecta un aumento en la productividad del $20 \%$

- Se proyecta una disminución en el precio del camarón del 10\%

- La alta administración de la empresa desea ver retribuida su inversión en 3 años o menos.

- Se tienen en cuenta los riesgos implícitos por cambios del precio en insumos de producción, para este caso en concreto, los precios de los materiales aumentarían de forma progresiva. 
- La empresa espera que haya un incremento salarial promedio del 3\% en el corto plazo y de $1,5 \%$ en el largo plazo.

- Debido a la adquisición de la nueva maquinaria se tiene presente un aumento en el consumo de combustibles, lubricantes, la compra de herramientas y servicios de mantenimiento.

Con estos puntos en mente, la Tabla 10 permite apreciar la matriz de presupuesto maestro diseñado para la microempresa, en este se resumen las fuentes de ingresos y egresos del negocio, siendo los primeros aquellos productos de la venta de camarón; mientras que entre los segundos se encuentran, en un principio, los producidos por costos incurridos (compras de materia prima, por beneficios a empleados, de depreciación y otros indirectos) y los categorizados como gastos (de origen administrativo y financiero $u$ otros no operacionales).

El objetivo de resumir esta información es obtener con ellos el total de flujo de caja de la entidad, el cual es calculado obteniendo la diferencia entre ingresos y egresos, del valor resultante se restan las participaciones a trabajadores, el impuesto a la renta a pagar, se suma la depreciación del PPE debido a que el mismo no es un egreso de efectivo real, y finalmente, se sumara el saldo inicial de caja de la empresa.

Una vez obtenido el total flujo de caja del negocio, será posible determinar entre varias otras cosas, la disponibilidad que tiene la empresa para adquirir maquinarias o insumos, y con ello mejorar la productividad, evaluando en conjunto la situación del negocio con el cálculo de otros indicadores determinantes para la toma de decisiones empresarial.

Tabla 10.

Matriz de presupuesto maestro de la empresa Punta Diamante Pundiaman S.A.

\begin{tabular}{|c|c|c|c|c|c|c|c|c|}
\hline \multicolumn{9}{|c|}{ Matriz de Presupuesto Maestro } \\
\hline \multicolumn{9}{|c|}{ Empresa Punta Diamante Pundiaman S.A } \\
\hline \multicolumn{9}{|c|}{ Al 31 de diciembre del 2019} \\
\hline DETALLE & INVERSIÓN & 2019 & INCREMENTO & 2020 & INCREMENTO & 2021 & INCREMENTO & 2022 \\
\hline INGRESOS OPERATIVOS & & $\$ 3.638 .575,38$ & & $\$ 4.147 .975,93$ & & $\$ 4.728 .692,56$ & & $\$ 5.390 .709,52$ \\
\hline Venta & & $\$ 3.638 .575,38$ & $14 \%$ & $\$ 4.147 .975,93$ & $14 \%$ & $\$ 4.728 .692,56$ & $14 \%$ & $\$ 5.390 .709,52$ \\
\hline \multicolumn{9}{|l|}{ Cuentas por cobrar } \\
\hline $\begin{array}{l}\text { TOTAL DE INGRESO } \\
\text { OPERATIVO Y NO } \\
\text { OPERATIVO }\end{array}$ & & $\$ 3.638 .575,38$ & & $\$ 4.147 .975,93$ & & $\$ 4.728 .692,56$ & & $\$ 5.390 .709,52$ \\
\hline \multicolumn{9}{|l|}{ EGRESOS } \\
\hline \multicolumn{9}{|l|}{ COSTOS DIRECTOS } \\
\hline \multicolumn{9}{|l|}{ MATERIAL DIRECTO } \\
\hline Larvas de Camarón & & $\$ 439.980,35$ & $10 \%$ & $\$ 483.978,38$ & $20 \%$ & $\$ 580.774,06$ & $25 \%$ & $\$ 725.967,57$ \\
\hline Balanceado & & $\$ 1.290 .303,47$ & $10 \%$ & $\$ 1.419 .333,82$ & $20 \%$ & $\$ 1.703 .200,58$ & $25 \%$ & $\$ 2.129 .000,73$ \\
\hline Probióticos & & $\$ 30.554,19$ & $10 \%$ & $\$ 33.609,61$ & $20 \%$ & $\$ 40.331,53$ & $25 \%$ & $\$ 50.414,41$ \\
\hline Alcón Melaza & & $\$ 84.360,12$ & $10 \%$ & $\$ 92.796,13$ & $20 \%$ & $\$ 111.355,36$ & $25 \%$ & $\$ 139.194,20$ \\
\hline
\end{tabular}




\begin{tabular}{|c|c|c|c|c|c|c|c|}
\hline Cal & $\$ 39.109,36$ & $10 \%$ & $\$ 43.020,30$ & $20 \%$ & $\$ 51.624,36$ & $25 \%$ & $\$ 64.530,45$ \\
\hline Zeolita & $\$ 8.555,17$ & $10 \%$ & $\$ 9.410,69$ & $20 \%$ & $\$ 11.292,83$ & $25 \%$ & $\$ 14.116,04$ \\
\hline Barbasco & $\$ 24.443,35$ & $10 \%$ & $\$ 26.887,69$ & $20 \%$ & $\$ 32.265,23$ & $25 \%$ & $\$ 40.331,53$ \\
\hline \multicolumn{8}{|l|}{$\begin{array}{l}\text { INVENTARIO DE } \\
\text { PRODUCTOS EN } \\
\text { PROCESO }\end{array}$} \\
\hline Productos en proceso & $\$ 131.398,57$ & $10 \%$ & $\$ 144.538,43$ & $20 \%$ & $\$ 173.446,11$ & $25 \%$ & $\$ 216.807,64$ \\
\hline \multicolumn{8}{|l|}{$\begin{array}{c}\text { COSTOS POR } \\
\text { BENEFICIOS A LOS } \\
\text { EMPLEADOS Y } \\
\text { HONORARIOS }\end{array}$} \\
\hline Nómina de producción & $\$ 254.411,04$ & $3 \%$ & $\$ 262.043,37$ & $1,5 \%$ & $\$ 265.974,02$ & $1,5 \%$ & $\$ 269.963,63$ \\
\hline $\begin{array}{l}\text { Beneficios sociales de } \\
\text { nómina de producción }\end{array}$ & $\$ 116.311,52$ & $3 \%$ & $\$ 119.800,87$ & $1,5 \%$ & $\$ 121.597,88$ & $1,5 \%$ & $\$ 123.421,85$ \\
\hline Aporte a la seguridad social & $\$ 42.342,63$ & $3 \%$ & $\$ 43.612,91$ & $1,5 \%$ & $\$ 44.267,10$ & $1,5 \%$ & $\$ 44.931,11$ \\
\hline $\begin{array}{c}\text { Honorarios profesionales } \\
\text { y dietas }\end{array}$ & $\$ 29.550,59$ & $3 \%$ & $\$ 30.437,11$ & $1,5 \%$ & $\$ 30.893,66$ & $1,5 \%$ & $\$ 31.357,07$ \\
\hline Jubilación patronal & $\$ 2.390,84$ & & $\$ 2.390,84$ & & $\$ 2.390,84$ & & $\$ 2.390,84$ \\
\hline Desahucio & $\$ 1.933,28$ & & $\$ 1.933,28$ & & $\$ 1.933,28$ & & $\$ 1.933,28$ \\
\hline \multicolumn{8}{|l|}{$\begin{array}{c}\text { COSTOS POR } \\
\text { DEPRECIACIONES } \\
\end{array}$} \\
\hline Depreciaciones & $\$ 58.083,69$ & & $\$ 58.083,69$ & & $\$ 58.083,69$ & & $\$ 58.083,69$ \\
\hline \multicolumn{8}{|l|}{$\begin{array}{l}\text { OTROS COSTOS } \\
\text { INDIRECTOS }\end{array}$} \\
\hline Roca Fosfórica & $\$ 8.160,00$ & $10 \%$ & $\$ 8.976,00$ & $10 \%$ & $\$ 9.873,60$ & $10 \%$ & $\$ 10.860,96$ \\
\hline Roca sedimentaria silicio & $\$ 6.800,00$ & $10 \%$ & $\$ 7.480,00$ & $10 \%$ & $\$ 8.228,00$ & $10 \%$ & $\$ 9.050,80$ \\
\hline $\begin{array}{l}\text { Carbonato de calcio M. } \\
\# 100\end{array}$ & $\$ 2.040,00$ & $10 \%$ & $\$ 2.244,00$ & $10 \%$ & $\$ 2.468,40$ & $10 \%$ & $\$ 2.715,24$ \\
\hline $\begin{array}{l}\text { Carbonato de calcio M. } \\
\quad \# 200\end{array}$ & $\$ 2.176,00$ & $10 \%$ & $\$ 2.393,60$ & $10 \%$ & $\$ 2.632,96$ & $10 \%$ & $\$ 2.896,26$ \\
\hline Cero Fish & $\$ 12.750,00$ & $10 \%$ & $\$ 14.025,00$ & $10 \%$ & $\$ 15.427,50$ & $10 \%$ & $\$ 16.970,25$ \\
\hline Combustibles & $\$ 82.501,77$ & $20 \%$ & $\$ 99.002,12$ & $20 \%$ & $\$ 118.802,55$ & $20 \%$ & $\$ 142.563,06$ \\
\hline Lubricantes & $\$ 40.049,40$ & $20 \%$ & $\$ 48.059,28$ & $20 \%$ & $\$ 57.671,14$ & $20 \%$ & $\$ 69.205,37$ \\
\hline $\begin{array}{l}\text { Herramientas, materiales y } \\
\text { repuestos }\end{array}$ & $\$ 199.617,17$ & $20 \%$ & $\$ 239.540,60$ & $20 \%$ & $\$ 287.448,72$ & $20 \%$ & $\$ 344.938,47$ \\
\hline $\begin{array}{l}\text { Mantenimiento y } \\
\text { reparaciones }\end{array}$ & $\$ 85.850,77$ & $20 \%$ & $\$ 103.020,92$ & $20 \%$ & $\$ 123.625,11$ & $20 \%$ & $\$ 148.350,13$ \\
\hline $\begin{array}{c}\text { Impuestos, contribuciones } \\
\text { y otros }\end{array}$ & $\$ 4.862,41$ & & $\$ 4.862,41$ & & $\$ 4.862,41$ & & $\$ 4.862,41$ \\
\hline Comisiones y similares & $\$ 31.695,70$ & & $\$ 31.695,70$ & & $\$ 31.695,70$ & & $\$ 31.695,70$ \\
\hline Otros & $\$ 247.376,53$ & & $\$ 247.376,53$ & & $\$ 247.376,53$ & & $\$ 247.376,53$ \\
\hline \multicolumn{8}{|l|}{ GASTOS GENERALES } \\
\hline \multicolumn{8}{|l|}{$\begin{array}{c}\text { GASTOS } \\
\text { ADMINISTRATIVOS }\end{array}$} \\
\hline $\begin{array}{l}\text { Gastos por beneficios a los } \\
\text { empleados y honorarios }\end{array}$ & $\$ 148.319,43$ & & $\$ 148.319,43$ & & $\$ 148.319,43$ & & $\$ 148.319,43$ \\
\hline Gastos por depreciación & $\$ 201,67$ & & $\$ 201,67$ & & $\$ 201,67$ & & $\$ 201,67$ \\
\hline $\begin{array}{l}\text { Pérdidas netas por deterioro } \\
\text { en el valor }\end{array}$ & $\$ 98.569,44$ & & $\$ 98.569,44$ & & $\$ 98.569,44$ & & $\$ 98.569,44$ \\
\hline Otros Gastos & $\$ 17.320,82$ & & $\$ 17.320,82$ & & $\$ 17.320,82$ & & $\$ 17.320,82$ \\
\hline \multicolumn{8}{|l|}{$\begin{array}{c}\text { GASTOS FINANCIEROS } \\
\text { Y OTROS NO } \\
\text { OPERACIONALES }\end{array}$} \\
\hline Costos de transacción & $\$ 1.212,29$ & & $\$ 1.212,29$ & & $\$ 1.212,29$ & & $\$ 1.212,29$ \\
\hline
\end{tabular}




\begin{tabular}{|c|c|c|c|c|}
\hline $\begin{array}{l}\text { Intereses con instituciones } \\
\text { financieras }\end{array}$ & $\$ 3.394,73$ & $\$ 3.394,73$ & $\$ 3.394,73$ & $\$ 3.394,73$ \\
\hline $\begin{array}{c}\text { Intereses pagados a } \\
\text { terceros }\end{array}$ & $\$ 7.054,67$ & $\$ 7.054,67$ & $\$ 7.054,67$ & $\$ 7.054,67$ \\
\hline TOTAL EGRESOS & $\$ 3.553 .680,98$ & $\$ 3.856 .626,33$ & $\$ 4.415 .616,20$ & $\$ 5.220 .002,26$ \\
\hline TOTAL DE INGRESOS & $\$ 3.638 .575,38$ & $\$ 4.147 .975,93$ & $\$ 4.728 .692,56$ & $\$ 5.390 .709,52$ \\
\hline TOTAL DE EGRESOS & $\$ 3.553 .680,98$ & $\$ 3.856 .626,33$ & $\$ 4.415 .616,20$ & $\$ 5.220 .002,26$ \\
\hline SALDO BRUTO DE CAJA & $\$ 84.894,40$ & $\$ 291.349,60$ & $\$ 313.076,36$ & $\$ 170.707,26$ \\
\hline $\begin{array}{c}15 \% \text { de participación de } \\
\text { trabajadores }\end{array}$ & $\$ 12.734,16$ & $\$ 43.702,44$ & $\$ 46.961,45$ & $\$ 25.606,09$ \\
\hline $\begin{array}{l}\text { UTILIDAD ANTES DE } \\
\text { IMPUESTOS }\end{array}$ & $\$ 72.160,24$ & $\$ 247.647,16$ & $\$ 266.114,90$ & $\$ 145.101,17$ \\
\hline $25 \%$ de impuesto a la renta & $\$ 18.040,06$ & $\$ 61.911,79$ & $\$ 66.528,73$ & $\$ 36.275,29$ \\
\hline $\begin{array}{l}\text { UTILIDAD NETA DEL } \\
\text { EJERCICIO (DESPUÉS } \\
\text { DE IMPUESTO A LAS } \\
\text { GANANCIAS) }\end{array}$ & $\$ 54.120,18$ & $\$ 185.735,37$ & $\$ 199.586,18$ & $\$ 108.825,88$ \\
\hline `+Depreciación & $\$ 58.285,36$ & $\$ 58.285,36$ & $\$ 58.285,36$ & $\$ 58.285,36$ \\
\hline SALDO TOTAL DE CAJA & $\$ 112.405,54$ & $\$ 244.020,73$ & $\$ 257.871,54$ & $\$ 167.111,24$ \\
\hline SALDO INICIAL DE CAJA & $\$ 315.247,48$ & $\$-8.003,86$ & $\$ 236.016,87$ & $\$ 493.888,41$ \\
\hline SALDO FINAL DE CAJA & $\$ 427.653,02$ & $\$ 236.016,87$ & $\$ 493.888,41$ & $\$ 660.999,65$ \\
\hline
\end{tabular}

Durante los últimos años se ha profundizado en mayor medida sobre la relación entre una correcta planificación estratégica, aplicada en conjunto con un presupuesto adecuado, pues, según señala Silva (2020), a nivel interno se identifican las fortalezas y debilidades que posee la empresa; se distribuyen los recursos adecuadamente, de tal forma que se lleva a cabo la estrategia formulada; en la empresa se ha declarado una misión y visión a largo plazo (4 años a más); se analizan las tendencias de los precios, costos, ventas, utilidad, etc., antes de realizar un presupuesto de forma efectiva.

En el presente caso se considera al presupuesto maestro como una base fundamental para el direccionamiento del negocio, estableciendo sus ingresos, costos y gastos, determinando el saldo de caja y la posibilidad de inversión en un periodo determinado, ya que según Delgado (2018), "el presupuesto maestro ayuda a pronosticar de la mejor manera la planeación de los recursos a necesitar para cumplir con los objetivos planteados".

Por otra parte, con los valores del total flujo de efectivo calculados es posible profundizar en el análisis del presupuesto maestro a través de dos indicadores financieros, en la Tabla 11 se puede apreciar el resultado obtenido por razón de VAN y TIR, teniéndose en cuenta una tasa de descuento del 15\%, la cual es un promedio para la mayoría de proyectos de inversión. En referencia al VAN fue posible calcular un valor de USD 1,220,269.19; por lo que es factible afirmar que la rentabilidad de la inversión dentro de 3 años, traída a valores presentes, es equivalente a tal monto, mismo que es muy superior a la inversión inicial de USD 32,734.00; el TIR por el otro lado, con un porcentaje de $1268 \%$, da espacio a denotar una tasa de retorno de la inversión mucho mayor a la tasa de descuento esperada del $15 \%$, de modo que nuevamente el indicador da a entender la factibilidad de la inversión en el largo plazo. 
Tabla 11.

Análisis de TIR y VAN de la empresa.

\begin{tabular}{cccccc}
\hline $\begin{array}{c}\text { Inversión } \\
\text { USD }\end{array}$ & Flujo 1 USD & Flujo 2 USD & Flujo 3 USD & Flujo 4 USD & $\begin{array}{c}\text { Tasa de des- } \\
\text { cuento }\end{array}$ \\
\hline$-32,734.00$ & $427,653.02$ & $236,016.87$ & $493,888.41$ & $660,999.65$ & $15 \%$ \\
\hline VAN & $1,220,269.19$ & & & & \\
\hline TIR & $1268 \%$ & & & & \\
\hline
\end{tabular}

Para el caso de la microempresa Punta Diamante Pundiaman S.A. esta no suele evaluar sus decisiones por factores cuantificables, por ello la aplicación de razones financieras por su parte, permitirá verificar la conveniencia de implementar un proyecto de inversión. En este punto, los indicadores del VAN y la TIR son razones de medición esenciales que, en base a lo que señala Orrala (2021), "garantizan una correcta toma de decisión financiera, ya que a través de la información que brinda se puede comprobar el nivel de riesgo o de beneficio".

De la misma forma, los resultados obtenidos en el presupuesto maestro de la empresa permiten ahondar en sus niveles de costo-beneficio para los periodos proyectados, en este aspecto, la Figura 2 evidencia que en 2019 este indicador tuvo un valor de 1,02; por lo que, por cada dólar de egresos registrados, la entidad obtiene \$1,02 por ventas de camarón realizadas. En 2020 el indicador aumenta a 1,08; en 2021 este disminuye a 1,07 y por último en 2022 el mismo vuelve a disminuir a 1,03; en general, es factible señalar que las razones de costo-beneficio obtenidas muestran un comportamiento creciente entre los años 2019-2020, y decreciente para periodos de 2020-2021 y 2021-2022.

Figura 2.

Análisis de razón costo-beneficio de la camaronera Punta Diamante Pundiaman S.A.

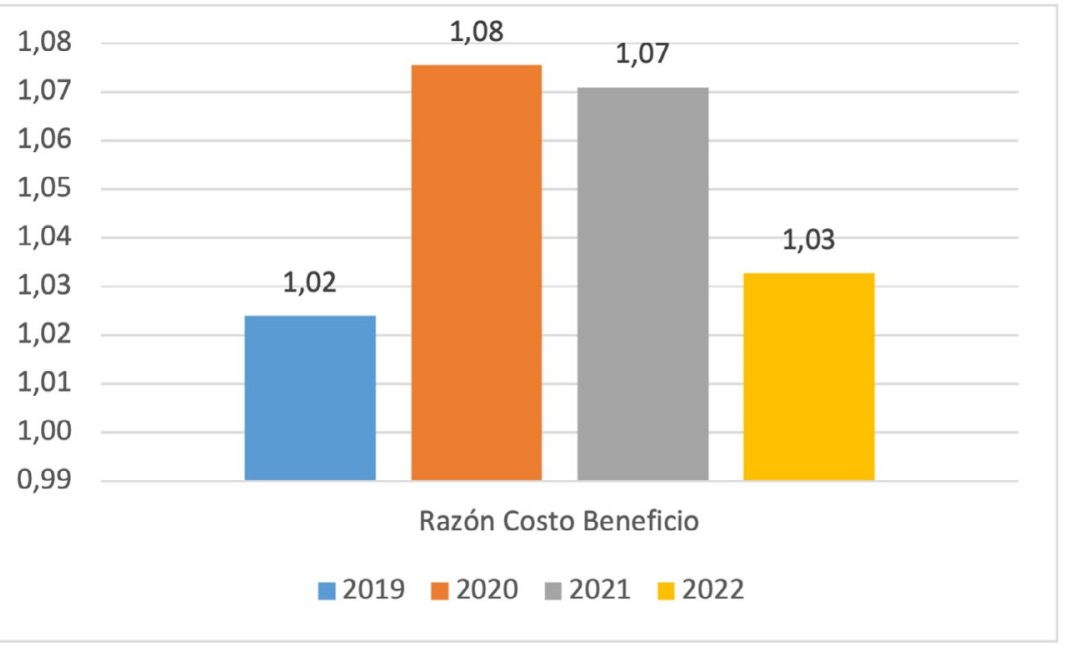




\section{Conclusiones}

Este trabajo está enmarcado en la gestión administrativa, direccionada a 416 microempresarios en los que se ha podido evidenciar estadísticamente la relación existente entre las variables características de la empresa con el nivel de gestión administrativa, siendo elementos determinantes para este ultimo la presencia de herramientas de planificación operativos y financieros, que contribuyan al fortalecimiento y desarrollo de la competitividad del microempresario orense.

Para ello se propuso la aplicación de herramientas estratégicas de planificación presupuestaria e indicadores financieros como instrumentos de control gerencial, que coadyuvan a una efectiva gestión administrativa, con la cual la empresa sea capaz de aumentar su competitividad.

En general, es factible asegurar que a través de los instrumentos financieros y administrativos propuestos, los emprendedores contarán con un modelo de dirección estratégica de enfoque gerencial que proporciona una base para la transparencia de su situación económica, y la capacidad de solventar sus egresos operativos mediante la utilización adecuada y oportuna de sus recursos, permitiéndole enfrentar varios de sus actuales desafíos como: el limitado acceso a financiamiento, la alta competitividad y la presencia de una crisis mundial producto de la pandemia por Covid-19, pues es prioritario impulsar la supervivencia del sector debido al alto impacto que tienen sobre el crecimiento económico, el número de puestos de empleo que generan y la composición en la estructura empresarial.

Ante lo expuesto en el párrafo anterior, la empresa Punta Diamante Pundiaman S.A. es una de las 416 microempresas, la misma que dio apertura para la aplicación de una planificación operativa y financiera, determinándose a través de estas, lo siguiente:

- La aplicación del direccionamiento estratégico contribuyó al cumplimiento de sus objetivos, a través de la evaluación de factores críticos que dieron paso a la propuesta de estrategias efectivas en responder a las necesidades de la empresa, aportando estas a la gestión administrativa en el direccionamiento adecuado en las operaciones de la organización Punta Diamante Pundiaman S.A.

- La ejecución presupuestaria de los periodos 2019 al 2022 muestra un saldo de efectivo de caja significativo, capaz de cubrir los egresos y el nivel de endeudamiento, evidenciándose un costo-beneficio de 1,08 como relevante durante el periodo 2020

- La evaluación de indicadores financieros de la mencionada empresa determina un retorno de la inversión, así como un valor actual neto positivo, comprobándose de este modo la viabilidad del proyecto de inversión según se establece en el presupuesto maestro.

El desarrollo de este artículo se hizo frente a dos limitantes: en principio la obtención de información para el estudio de caso de la camaronera Punta Diamante Pundiaman S.A. que enfrentó varios contrapiés por el sigilo empresarial y la indisposición de los directivos a colaborar en la indagación, así como la inexistencia de planes organizacionales, que son base sobre el cual se edifica una planificación estratégica. 
Es necesario que futuros estudios tengan en cuenta estos factores para ampliar los horizontes del tema en relación a la gestión empresarial, el impacto del desarrollo de planes de direccionamiento en la microempresa al largo plazo y el rol de los organismos de control ante una problemática permanente por la carencia de conocimientos de los emprendedores en las áreas administrativas, contables, tributarias, laborales, entre otras. 


\section{Referencias}

Amaguaña, A., Amaguaña Arredondo, A, Amaguaña, D., \& González, A. (2017). Planificación estratégica para la empresa "La Negra Eva", ubicada en el Cantón Machala, Provincia El Oro, Ecuador. Gestión, Ingenio y Sociedad, 2(2), 118-127. http://gis.unicafam.edu.co/index.php/gis/article/view/54

Chávez, M. (2016). Desarrollo de un análisis FODA y diagrama de pareto en la camaronera Oceanproduct CIA. LTDA. para mejorar su posicionamiento estratégico. [Tesis de grado, Universidad Técnica de Machala]. http://repositorio.utmachala.edu.ec/handle/48000/12605

Delgado, J. (2018). Los presupuestos, herramientas necesarias para la elaboración del flujo de caja proyectado. [Tesis de grado, Universidad Técnica de Machala]. http://repositorio.utmachala.edu.ec/handle/48000/10938

Dini, M., \& Stumpo, G. (coords.). (2020). "Mipymes en América Latina: un frágil desempeño y nuevos desafíos para las políticas de fomento. Síntesis", Documentos de Proyectos (LC/TS.2019/20), Santiago, Comisión Económica para América Latina y el Caribe (CEPAL). https://repositorio.cepal.org/handle/11362/44603

Espinoza, J., Vázquez, I., Álvarez, M., \& Valenzuela, R. (2018). Plan estratégico para una microempresa del giro comercial en ciudad Obregón. Revista de Investigación Académica Sin Frontera, 11(28), 36. https://doi. org/10.46589/rdiasf.v0i28.200

Gamez, A., Morales, M., \& Ramírez, C. (2018). Estado del arte sobre problemáticas financieras de las pymes en Bogotá, Colombia y América Latina. Económicas Cuc, 39(2), 77-94. https://doi.org/10.17981/econcuc.39.2.2018.05

Hernández, R., Fernández, C., \& Baptista, M. (2014). Metodología de la Investigación. Editorial Mc Graw Hill.

Molina, R., López, A., \& Schimtt, C. (2016). Factores que influyen en los problemas del emprendimiento de las Mipymes: Una percepción de los expertos. Revista Internacional Administración \& Finanzas, 9(1), 95-113.

Neciosup, M. (2017). La Planificación Operativa y su Efecto en la Situación Económica y Financiera de los Restaurantes del Distrito de Magdalena De Cao, Año 2016. [Tesis de grado, Universidad César Vallejo]. https://hdl.handle.net/20.500.12692/11930

Oranday, S., Vázquez, O., \& Mota, Ó. (2019). Metodología de la investigación en las ciencias administrativas (1ra edición). Universidad Autónoma de Coahuila.

Orrala, W. (2021). Herramientas Financieras en la Valoración de Inversiones en la PYMES del Ecuador. [Tesis de grado, Universidad Estatal Península de Santa Elena]. https://repositorio.upse.edu.ec/handle/46000/5881 
Paladines, S., Moreno, V., \& Vásconez, L. (2020). Implicaciones contables de los efectos del Covid-19 en el sector camaronero del Ecuador. Revista Arbitrada Interdiciplinaria KOINONIA, 5(4), 243-272. https://doi. org/10.35381/r.k.v5i4.957

Pérez, S., \& Pérez, F. (2016). Planificación financiera de las empresas: el rol de los impuestos o tributos. Revista Publicando, 3(8), 563-578. https://dialnet.unirioja.es/servlet/articulo?codigo=5833413

Pibaque, M., Álvarez, A, \& Soledispa, S. (2020). La importancia de la aplicación de matrices de la planificación estratégica en el sector microempresa de las bibliotecas-cafererías. FIPCAEC, 5(3), 22-44. https://doi. org/10.23857/fipcaec.v5i5.279

Rodríguez, G, Cano, E., \& Ruiz, A. (2019). La competitividad en las microempresas en Manta 2019. Revista San Gregorio, 1(35), 51-69. https://doi.org/10.36097/rsan.v1i35.1141

Rodríguez, J., Ochoa, L., \& Mariscal, Z. (2020). Estrategias comerciales para mejorar la gestión en las microempresas ecuatorianas post covid-19. Revista Universidad y Sociedad, 3(2017), 191.

Silva, H. (2020). Planeamiento estratégico y presupuesto en las micro y pequeñas empresas textiles del emporio comercial de Gamarra. Quipukamayoc, 28(58), 27-34. https://doi.org/10.15381/quipu.v28i58.19261 
Copyright (c) 2022 Marjorie Katherine Crespo García, Martin Andrés Romero Lalangui, Armando José Urdaneta Montiel y Andreína Inés González Ordóñez

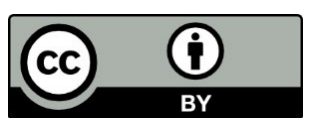

Este texto está protegido bajo una licencia internacional Creative Commons 4.0.

Usted es libre para Compartir - copiar y redistribuir el material en cualquier medio o formato - y Adaptar el documento - remezclar, transformar y crear a partir del material-para cualquier propósito, incluso para fines comerciales, siempre que cumpla las condiciones de Atribución. Usted debe dar crédito a la obra original de manera adecuada, proporcionar un enlace a la licencia, e indicar si se han realizado cambios. Puede hacerlo en cualquier forma razonable, pero no de forma tal que sugiera que tiene el apoyo del licenciante o lo recibe por el uso que hace de la obra.

$\underline{\text { Resumen de licencia - Texto completo de la licencia }}$ 